Meeting of the International Society for Traumatic Stress Studies, 1993 (available at http://www.pdhealth.mil/guidelines/appendix4.asp).

27 Beck AT, Steer RA, Brown GK. Manual for the Beck Depression Inventory (2nd edn). Psychological Corporation, 1996

28 Spitzer RL, Kroenke K, Williams JB. Patient Health Questionnaire Primary Care Study Group Validation and utility of a self-report version of PRIME-MD: the PHQ-15 primary care study. JAMA 1999; 282: 1737-44.

29 WHOQOL Group. Development of the World Health Organization WHOQOLBREF quality of life assessment. Psychol Med 1998b; 28: 551-8.

30 Vasterling JJ, Brailey $\mathrm{K}$, Proctor SP, Kane R, Heeren T, Franz M. Neuropsychological outcomes of mild traumatic brain injury, post-traumatic stress disorder and depression in Iraq-deployed US Army soldiers. Br J Psychiatry 2012; 201: 186-92.

31 Brenner LA, Vanderploeg RD, Terrio H. Assessment and diagnosis of mild traumatic brain injury, posttraumatic stress disorder, and other polytrauma conditions: burden of adversity hypothesis. Rehabil Psychol 2009; 54: 239-246.

32 Iverson GL. Outcome from mild traumatic brain injury. Curr Opin Psychiatry 2005; 18: 301-17.

33 Fear NT, Jones E, Groom M, Greenberg N, Hull L, et al. Symptoms of postconcussional syndrome are non-specifically related to mild traumatic brain injury in UK armed forces personnel on return from deployment in Iraq: an analysis of self-reported data. Psychol Med 2009; 39: 1379-87.

34 Vanderploeg RD, Belanger HG. Screening for a remote history of mild traumatic brain injury: when a good idea is bad. J Head Trauma Rehabil 2013; 28: $211-8$.

35 Iverson GL, Brooks BL, Ashton VL, Lange RT. Interview versus questionnaire symptom reporting in people with the postconcussion syndrome. I Head Trauma Rehabil 2010; 25: 23-30.

36 Maestas KL, Benge JF, Pastorek NJ, LeMaire A, Darrow R. Factor structure of posttraumatic stress disorder symptoms in OEF/OIF veterans presenting to a polytrauma clinic. Rehabil Psychol 2011; 56: 366-73.

37 Veterans Affairs/Department of Defense. VA/DoD Clinical Practice Guideline Management of Concussion/Mild Traumatic Brain Injury. Veterans Affairs/ Department of Defense, 2009.

38 Nelson NW, Hoelzle JB, Doane BM, McGuire KA, Ferrier-Auerbach AG, Charlesworth MJ, et al. Neuropsychological outcomes of U.S. Veterans with report of remote blast-related concussion and current psychopathology. J Int Neuropsychol Soc 2012; 18: 845-55.

39 Jones N, Fear NT, Rona R, Fertout M, Thandi G, Wessely S, et al. Mild traumatic brain injury (mTBI) among UK military personnel whilst deployed in Afghanistan in 2011. Brain Injury 2014; 28: 896-99.

\title{
Locked in
}

\section{Andrew Gardner}

Few medical students get the opportunity to experience a psychiatric intensive care unit (PICU) during their training. I had little idea what to expect - my best guess was some very physically ill patients who also happened to be psychotic. For some reason, it never crossed my mind it would be the nature of the patients' psyche that would denote their place of institution. Perhaps this is because as medical students, or even the social group from which we usually arise, we have little exposure to these extremes of mental illness.

My naivety made my first impression of the ward all the more surreal: I could not quite grasp the point of it all. Most of the time nurses just stood around with their patients, until every so often one of the patients 'kicked off' and the nurses restrained each available limb, administered sedating medication and escorted them into another, slightly more Spartan (de-escalation) room, until they cooled down. Stern words were juxtaposed with reassurance. The doctors were hands off, directing changes in medication and mostly suggesting patients' management from afar. What were we actually doing here, if not just acting as childminders? Were these patients even really ill? It took me until my fourth and final week to understand just how wrong my interpretation was. At first glance, compassion is easy to miss in PICU.

I have learnt that a great majority of psychiatry is about re-forging relationships; be it those between the ideas darting around a patient's mind or with the individuals around them. While doctors contribute diagnosis, prognosis and a leadership in such an unpredictable spectrum of disease, it is primarily nurses who manage patients' illness day to day. They constantly challenge and redirect misaligned thoughts, the effect of which pharmacology can usually only serve to dampen or numb. As medical students our only true requirement is to observe, interview and present patients for exam practice and our own psychiatric curiosity: a shadow of our future role. Yet, a nursing student is expected to act as if they were a nurse, with full-time responsibilities. This difference undermines an education in the interdisciplinary nature of psychiatry. As a student, without immersion in the constant dialogue of patient care, the subtlety of psychiatry is lost.

Psychiatry is a specialty which must embrace multidisciplinary care and champion it for the National Health Service. Interdisciplinary teamwork should also be reflected in student training, a move which will serve to degrade the old barriers of tribalism, which are often still evident in healthcare today. For example, each medical student could be attached to a nurse mentor and should be encouraged, if not compelled, to contribute towards patient care. Without a proper understanding of how to manage psychiatric illness, if not now, then how as an F1 in A\&E? I went into PICU wanting psychiatry to have simple solutions, which in my mind involved various coloured pills targeting well-defined disease. Now I realise, perhaps that's not as easy as it seems. 